\title{
Smart linguistic-based cognitive acquisition model in language and communication skills development for ASD children: A framework analysis
}

\author{
Mimi Fitriana ${ }^{1 *}$, Nurul Nisa Omar $^{2}$, and $\mathrm{Ng}$ Sok Choo ${ }^{2}$ \\ ${ }^{1}$ School of Science \& Psychology, Faculty of Arts \& Science, International University of Malaya- \\ Wales, Jalan Tun Ismail 50480 Kuala Lumpur, Malaysia \\ ${ }^{2}$ School of Communication \& Technology, Faculty of Arts \& Science, International University of \\ Malaya-Wales, Jalan Tun Ismail 50480 Kuala Lumpur, Malaysia
}

\begin{abstract}
Cognitive acquisition is the ability to improve cognition, brain health, and neural communication supporting the development of cognitive skills among children with Autism Spectrum Disorder (ASD). This concept paper is to establish the Framework to assist in the understanding of how the Model can be used to improve the cognitive development of ASD children. Such a Model will proliferate sustainable methods of learning and teaching to assist parents, guardians, and instructors of ASD children implementing the intervention activities. The Smart Linguistic-based Cognitive Acquisition Model, in this paper, is proposed to be developed in four phases. Phase 1 seeks to identify the components and features of cognitive skills acquisition, leading to a conceptual model supporting the language and communication development of ASD children. Phase 2 involves interviews with 20 professionals for verifying the selected components. Phase 3 involves incorporating components and features identified in phase 1 and verified in phase 2 into a Smart Linguistic-based Cognitive Acquisition Model. Phase 4, is to establish the conceptual model that incorporated Cognitive Acquisition in Language and Communication skills for ASD children within the Model framework. Thus, this concept paper would contribute to the implementation of sustainable learning and teaching for ASD children's cognitive development.
\end{abstract}

\section{Introduction}

Sustainable learning in education has been recognized in diverse institutions as an approach in enriching the curricula and teaching methods used by the educators. The approach has been used to elucidate the instructions and other learning-teaching capacities in different contexts. Such a technique in education also helps to enumerate the potential development of learning among the special need students (Clark, 2013; Hays \& Reinders,

\footnotetext{
* Corresponding author: mimifitriana@iumw.edu.my
} 
2020). In Malaysia, various strategies have been conducted to implement an inclusive sustainable learning in education system to help parents and guardians, teachers and other professionals managing ASD children through autism education. However, such an inclusive education system needs to be complemented by the support of a comprehensive education to help ASD children develop their cognitive and skills ability (Frith \& Happe, 1994; Jones, 2014; Krog, 2010; Spain et al., 2017).

A cognitive acquisition programme has been implemented to examine the impact of the activity program in classrooms. Cognitive acquisition derives from the basic idea that learning arises when a person interacts with stimulation. Such stimulation from sensory capacity initiates thinking ability and stimulates language regulation and communication production to eventually improve learners' language development and communication skills (Laurent et al., 2004; Karen et al, 2008). Stimulation-based intervention programme also helps improve neurological function to connect the brain areas of the learners (Kong, 2010) and is accessible for any given task. It uses developmental activities and provides a level of immediate improvement (Dennison, 2003; Kosmas et al., 2019). The current cognitive acquisition activities could address a wide range of academic and behavioural issues (Dennison, 2003), which initiate motoric activities. However, there are limited studies that measured its effect on the language and communication skills development induced in children with ASD (Lindsay et al, 2013).

Early research scholars have shown the importance of physical movement in children's cognitive and functioning in stimulating the ability of their mental state which is regulated by the neural communication in the brain (Delacato, 1959, 1974; Kephart, 1975; Ayres, 1979). Other contemporary researchers have also found the integration of brain-muscles movement coordination for the ASD children when stimulated with pictures by the professionals in schools to reflect neural organization and to provide stimulation to neurological systems that are required for optimal development and functioning in cognitive and motor functions (Dennison, 2003; Fang et al., 2019; Have et al., 2018; Krog 2010; Jones, 2014; Skinner et al., 2009). As a result, mastering basic movement skills at an early age will ease further motor skill acquisition and increase learners' capacity through pleasant physical activity experiences (Jones, 2014; Sparapani et al, 2016). Such overwhelming findings invigorates the current paper to focus on framework analysis in its attempt to investigate language and communication skills acquisitions of ASD children through the use of an effective selected cognitive skills acquisition as easy access for the professionals to train others who require the use of such conceptual framework. However, the study does not involve the physical motoric function of the ASD children as the basic verbal intelligence technique, it rather uses the cognitive acquisition components which will be presented as the stimulation to represent the functions of verbal intelligence to be assessed through different use of reading, writing, pictures presentation, etc., for the effectiveness of the conceptual framework to develop. The concept paper will propose its research focus on the use of the effective components of cognitive acquisition movement-based learning that are related to language development and communication skills acquisition. In line with that aim, the current paper needs to propose a framework that includes instruction and lesson delivery of language and communication proficiency using Smart Linguistic-based Cognitive Acquisition techniques. The effectiveness of the established framework will be evaluated in terms of its performance, accuracy, and its reliability. It will certainly be a good start before developing a working system to assist parents and guardian of ASD children to be able to help their children in the instructions of the lesson delivery for teaching language and communication skills.

The effectiveness of cognitive acquisition stimulation in helping ASD children has been proven by various researchers, especially in their cognitive improvement (Frith \& Happe, 
1994; Jones, 2014; Krog, 2010; Abduh \& Tahar, 2018) and the cognitive acquisition training provided for the ASD professionals has been immensely increased to help the ASD children engage more in their performance. Abduh and Tahar (2018) highlighted the importance of cognitive functions of ASD children in working memory where exercises and interventions were provided to the children in a pre- and post-quasi-experiment, indicating the success of exercises and interventions in Digit Span Memory and Spatial Memory Skills. The study extensively elaborated on the capacity of ASD children to improve their cognitive ability using cognitive acquisition interventions and exercises (Abduh \& Tahar, 2018). Other studies also indicated the effectiveness of Cognitive acquisition intervention activities to improve language skills of ASD children. Several studies indicated the important use of advanced mobile technologies for Cognitive acquisition activities and interventions for the professional (Ayres, Mechling \& Sansosti, 2013; Bono et al., 2016). However, language and communication skills for the ASD children are best trained by stimulating the brain using movements intervention training involving verbal intelligence to produce verbal expression by displaying some objects or pictures or some vocalization (Low \& Lee, 2011). Such an approach was proposed for the teachers in school to teach ASD children with the different severity level. The proper conceptual framework to be used by teachers, parents, guardians and other professionals working with ASD children to improve their language and acquisition skills is yet to be developed in Malaysia. Therefore, the current article exposes the potential research aims to establish the framework based on the conceptual model which is named as Smart Linguistic-based Cognitive Acquisition Model.

Smart Linguistic-based Cognitive Acquisition Model is a proposed framework to introduce to the potential users, the professionals, teachers, guardians, parts, etc., those who are working and assisting the ASD children in their learning capacity. The framework is derived from the selected components/features which will be later identified by using the Theory of Mind (ToM) and some other model perspectives. 'Theory of Mind' refers to the cognitive capacity to attribute mental states to self and others (Goldman, 1989). It is also based on the ToM framework proposed by Astington and Barriault (2001) on two aspects; internally (i.e., subjective) which focuses on an individual's capacity to form and use mental representations in order to create and sustain a sense of the self and world, and externally (i.e., objective), which is represented by actions within the world of social relationships, and so is intimately connected to everyday social interactions (Hughes \& Leekam, 2004). Therefore, in its selective identification of the cognitive acquisition components and features for ASD language and communication skills, the current paper utilizes the concept of ToM for this purpose. Smart Linguistic-based Cognitive Acquisition Model is named to suit the cognitive acquisitions which consist of many skills and only some skills which are related to language and communication will be selected carefully. The name of the Model with the 'Smart' word is to indicate verbal intelligence which will be used to assess the ability of ASD children in their language and communication. Therefore, this study seeks to develop a cognitive acquisition conceptual framework to help improve neural communication and language deficits among children with ASD in Malaysia, making it as easy access for parents and guardians of ASD children in improving their language and communication skills acquisitions.

\section{Methodology}

The methodology is based on approaches in Theory of Mind (mental state theory) (Goldman, 2012), which support the design and development of the contents of the conceptual model of cognitive acquisition Smart Linguistic-based Cognitive Acquisition 
framework. It is also based on the ToM framework proposed by Astington and Barriault (2001) on two aspects, which are internal (i.e., subjective), focuses on individual's capacity to form and use mental representations in order to create and sustain a sense of the self and world, and external (i.e., objective), represented by actions within the world of social relationships, and so is intimately connected to everyday social interactions (Hughes \& Leekam, 2004). This concept paper proposes three research objectives; 1) to identify the components and features of a Cognitive acquisition programme that supports the development of language and communication acquisition skills of ASD children, 2) to incorporate the components and features identified in (1) into a framework for development of Smart Linguistic-based Cognitive acquisition Model, and 3) to evaluate the effectiveness of the proposed Smart Linguistic-based Cognitive acquisition Model in terms of its concept's functionality and accuracy from the potential users. Such objectives are in line with the development of the three research questions to support this qualitative method for the framework analysis; 1) what are the components and features of Cognitive acquisition that support the development of language and communication skills of ASD children?, 2) how can the components and features identified in (1) be incorporated into a Smart Linguisticbased Cognitive Acquisition Model?, and 3) what is the effectiveness level of the established framework identified in (2)?

\section{Sample}

There will be a selection of 20 ASD professionals from 4 disciplines experts; psychology, communication, linguistic, and IT expert to evaluate 5 components that will be established from the theory of mind. in Psychology, Language and Communication with substantial experience in cognitive skills acquisition programmes for ASD children in cognitive stimulation will be purposively identified from different autism centres. The purpose of recruiting the 20 sample is to identify the proper selection of cognitive skills acquisition components, specifically language and communication abilities of ASD children to be incorporated in the conceptual model of Smart Linguistic-based Cognitive Acquisition. This selection is particularly described further in phase 1 of research procedure.

\section{Procedure}

The study consists of four phases (i.e. identifying and analyzing components and features of the Cognitive acquisition, from the existing theories and models perspective, supporting the language and communication skills development of ASD children, interviewing the ASD professionals, incorporating components and features identified in phase 1 and verified in phase 2 into a Smart Linguistic-based Cognitive Acquisition Model, and establish the conceptual model that incorporated Cognitive Acquisition in Language and Communication Skills for ASD children within the Smart Linguistic-based Cognitive Acquisition Model framework)

\section{Phase 1}

Identifying and analyzing components and features of Cognitive acquisitions supporting the language and communication skills development of ASD children. Cognitive acquisition components will be identified and selected based on the existing theories and models perspective that support the language and communication skills acquisition development of ASD children. The selected components will be validated by content experts to ensure that 
these components would be the most appropriate for improving the language and communication skills acquisition development and are suitable to be used by the Malaysian ASD children population. This phase will involve a systematic review/meta-analysis in the selection of the components/features of cognitive acquisitions for language and communication development of ASD children. Using different perspectives from the theories and other past studies to assist the researchers in the selection of the cognitive skills acquisition components. $\mathrm{n}$ this stage, data on ASD language and communication skills acquisition will be collected in order to identify and select some relevant research related to the features/components of cognitive acquisition of ASD children. This is also to study the previous research which discussed the components of language and communication skills of ASD children.

\section{Phase 2}

Interviews with 20 professionals in cognitive skills acquisition for language and communication components. After completing the selection process, the ASD professionals will be interviewed face to face by trained enumerators based on an interactive flexible interview guide. The enumerators will be the three experts in psychology, IT, and communication. They will be asked about their experiences, perspective of the process and impact of the selected components on the language and communication skills acquisition development of ASD children. The interviews will be recorded and transcribed using content analysis to identify the most appropriate components and features of ASD cognitive skills acquisition to be incorporated into a conceptual model of Smart Linguistic-based Cognitive Acquisition Model. The professionals will be interviewed on the validation of the selected cognitive skills acquisition components to be used, later, by those other professionals and parents who educate and train the ASD children's ability in language and communication. After the interview with 20 content expert ASD professionals, it will be transcribed to develop coding. Thematic analysis will then identify specific themes generated for each component in language and communication to be used in more details by the ASD teachers, guardians, parents etc., later, for lesson delivery. Those selected components will be used to be administered to ASD children. The administration process will be later observed and rated by two observers to obtain inter-observers reliability. The components will be presented in the Model framework to be used by the professionals who educate and train the ability of ASD children in language and communication to improve.

\section{Phase 3}

Incorporating components and features identified in phase 1 and verified in phase 2 into a Smart Linguistic-based Cognitive Acquisition Model. The specific selected and verified components and features of Cognitive acquisition will be used in facilitating the development of Smart Linguistic-based Cognitive Acquisition Model. After the selection of the components and features identified in phase 1 and verified in phase 2 by the ASD professionals, the themes generated from the thematic coding in phase 2 via NVivo, will be presented to facilitate the development of a Smart Linguistic-based Cognitive Acquisition Model. In this phase, careful observation will be given to the details of the generated themes from the thematic coding. The researchers will analyse the use of the specific and selected features and components of cognitive acquisitions with the development of model assessment before establishing the concept into a Smart Linguistic-based Cognitive Acquisition Model framework. The specific details of generated themes from thematic coding show the 
conceptual framework incorporating the Model to be used by the professionals working with ASD children later. Each generated themes in each component of language and communication will be later evaluated by the professionals working with ASD children to help improve the cognitive skills acquisition of the children. The testing and evaluation will be in the form of Smart Linguistic-based Cognitive Acquisition assessment prepared by the researchers to be used by the professionals working with ASD children.

\section{Phase 4}

Establish the conceptual model that incorporated Cognitive Acquisition in Language and Communication Skills for ASD children within the Smart Linguistic-based Cognitive Acquisition Model framework. This final phase will involve the establishment of a Smart Linguistic-based Cognitive Acquisition Model, produced and presented in the Model Framework Assessment to facilitate the professionals, teachers, guardians, parents, etc., working with the ASD children in improving the language and communication skills of the children. This phase will have all assessment details to be a ready-used Model Framework assessment which will be utilised by the researchers to test and evaluate the Model. In this phase, the Model Framework will be hypothetically evaluated again using a quantitative survey method to disseminate the professionals working with the ASD children. The questionnaires will be adopted and adapted to suit the selected previous generated themes in phase 3 incorporating the specific features and components of cognitive acquisition. Using the purposive sampling technique in this final phase will help the researcher to analyse the use of this conceptual model for the concept's functionality and accuracy from the potential users which will establish an accurate, reliable and valid Smart Linguistic-based Cognitive Acquisition Model in this current study, to help improve language and communication skills of ASD children, thus enhance their cognitive development. In this final stage, the professionals, teachers, guardians and parents of the ASD children will be given the questionnaires for their feedback on the Model. The analysis will be run to test the hypothesis of the current study that the Smart Linguistic-based Cognitive Acquisition Model can facilitate the cognitive acquisition skills of language and communication development among ASD children.

\section{Discussion}

This concept paper proposes a framework analysis which discussed the potential research work and investigation on the qualitative method to allow the researchers to collect data and to analyse data in accordance with main ideas to develop themes. This concept paper is in line with Malaysia's policy on equal educational opportunities for all children. The study is particularly relevant to the Malaysia Pre-school and Higher Secondary Education Blueprint 2015-2025, particularly Shift 7 and Shift 9. In Shift 7 - Leverage ICT to Scale-up Quality Learning across Malaysia - Providing Internet access and virtual learning environment, augmenting online content, and maximizing the use of ICT for distance and self-paced learning. In Shift 9 - Partners with Parents, Community, and Private Sector at Scale - Equip every parent to support their child's learning through a parent engagement toolkit and online access to their child's in-school-progress. It also addresses UNESCO's SDG goal 4 Quality Education of 4.5 Outcome Target - Gender Equality and Inclusion - eliminating gender disparities in education and ensuring equal access to all levels of education and vocational training for the vulnerable, including persons with disabilities, indigenous peoples, and children in vulnerable situations. Besides, the study is also applicable to the objective of the 
Ministry of Women, Family and Community Development, Department of Social Welfare, Objective 4 - Enhancing the community's well-being through professional social welfare services, social development, and a strategic sharing of responsibilities.

In its effort for the community and society benefits, this conceptual framework paper helps to have improvement in ASD cognitive stimulation activities of language and communication skills with the use of Smart Linguistic Conceptual Model, improvement in the quality of teaching and learning in special, mainstream and inclusion criteria of education, and improvement of language and communication skills via Smart Linguistic-Cognitive Based Model.

As this concept paper seeks to identify the features in cognitive acquisition activities which will be used by parents, guardians, teachers, or other professionals in Malaysia to improve the language and communication skills of children with ASD, Smart Linguisticbased Cognitive Acquisition Model approach is introduced for ASD lesson delivery methods. Understanding the features and components of cognitive acquisition is important due to the typical characteristics of ASD children in language impairment and communication acquisition skills deficit (Bergland, 2014; Horlin et al, 2014; Krong, 2014; Robin, 2017; Nagarkar, et al., 2018) and would allow for addressing differences among ASD children. To date, past studies have yet to isolate and examine the features and components of cognitive acquisition activities that work well including investigating the extent to which the various features and components support ASD children learning especially towards their language and communication proficiency.

What current studies have shown is how effective cognitive acquisitions are. The current cognitive skills, used by professionals, is proven indispensable by many studies to improve the impairment in general (Sterling-Turne, et. al, 2001, Qi Meng, 2017) as well as in communication (Bergland, 2014; Kall et al., 2014; Lee, 2014) among ASD children. However, such studies only indicated the benefits of the cognitive skills with activities in the effort to increase the achievement of social and academic skills of ASD children (Hayes, et al., 2013; Razali et al., 2013; Vazou \& Smiley-Oyen, 2014) as well as to increase their involvement in academic performance through the use of physical movements (Frith \& Happe, 1994; Sterling-Turne, et. al, 2001, Jones, 2014; Krog, 2010; Qi Meng, 2017) with positive effects on the brain and cognitive function of ASD children (Donelly et al., 2016). Additionally, the use of receptive and expressive language for children in ASD is mainly related to their cognitive level (Kjellmer, et al., 2011). Nonetheless, studies on the selected components and features of cognitive acquisitions which specify the function of language and communication skills of ASD children are yet to be found. Research on the selection and isolation of the features and components in language and communication acquisition skills have yet to be compiled for the establishment of a concept by using a Smart Linguistic-based Cognitive approach to stimulate the brain. The use of Smart Linguistic-based Cognitive in stimulating the brain activities of ASD children appears to have yet to be developed.

Therefore, the current study seeks to establish a conceptual framework that can be used in the future as a reference model before developing a technology-based lesson delivery for ASD children. This is to provide parents and guardians of ASD children with the programme to improve their language and communication acquisition skills deficiency. Additionally, fundamental study of merging the Cognitive Acquisition in Language and Communication proficiency with Smart Linguistic-based Cognitive Acquisition Model is important to ensure the framework is valid and reliable before it can be turned into a system that could potentially be used on computer operating systems as well as in the form of an App, such as Android and IOS. The introduction of such software and/or Application will make it very convenient for parents, caretakers, and guardians of children with ASD to guide the children in doing their exercises and enable them to practice intervention at their convenience. Such a 
conceptual model of cognitive acquisition is also beneficial to foster students' motor functions to interact with their peers and other people in their surroundings.

The concept will feature instructions that fit Language and Communication development which is also an emerging need of ASD education which impact the rise of academic achievements among students in schools, especially learning-disabled students (Nagarkar et al., 2018). The focus on academic performance among students is also from the use of accurate instructions which influence their learning ability, thus increasing achievements in content-based learning (Lin \& He, 2019). Thus, it fulfils the demand of the learning for sustainability to further enhance the needs of autism education which also aims to provide the quality education with equality among Malaysian children. For this purpose, the current paper, therefore, will create a cognitive acquisition conceptual framework using the Smart Linguistic-based Cognitive Acquisition Model, where instructions of the cognitive acquisition skills and activities are presented with clear instruction. As the model will be presenting the selected components from the current cognitive skills acquisition features, obtained from the ToM frameworks and other models' perspectives, the current paper will develop its own conceptual framework of Cognitive skills acquisition functions as easy access for parents and guardians in Malaysia, to help their ASD children improving their language and communication acquisitions, to be used at their convenience, as part of autism education.

\section{References}

Abduh, B., \& Tahar, M. M. (2018). The Effectiveness of Cognitive acquisition and Brain Training Intervention on Working Memory Performance of Student with Learning Disability. Journal of ICSAR, 2(2); 105-111.

Alhowikan, A., M. (2019). Benefits of physical activity for autism spectrum disorders: A systematic review. Saudi Journal of Sports Medicine, 16(3); 163-167.

Astington, J. W. \& Barriault, T. (2001). Children's theory of mind: How young children come to understand that people have thoughts and feelings. Infants and Young Children 13, $1-12$.

Ayres, K. M., Mechling, L., \& Sansosti, F. J. (2013). The use of mobile technologies to assist with life skills/independence of students with moderate/severe intellectual disability and/or autism spectrum disorders: considerations for the future of school psychology. Psychology in the Schools, Vol. 50(3): 259-271.

Berglan, C. (2014). Research links autism severity with motor skill deficiencies. Psychology Today. Retrieved from https://www.psychologytoday.com/us/blog/the-athletes-way/201404/research-links-autismseverity-motor-skill-deficiencies

Bono, V., Narzisi, A., Anne-Lise J., Tilmont, E., Hommel, S., Jamal, W., Xavier, J., Billeci, L., Maharatna, K., Wald, M., Chetouani, M., Cohen D., \& Muratori, F. (2018). Goliad: A Gaming Platform for home-Based Intervention in Autism - Principles and design. Frontiers in Psychiatry, 7(70); 1-16.

Clack, K., E. (2013) Ecological Intelligence and Sustainability Education in Special 
Education. A Multicultural Interdisciplinary Inquiry, 38-45. Retrieved from https://files.eric.ed.gov/fulltext/EJ1045851.pdf

Camarata, S. (2014). Early identification and early intervention in autism spectrum disorders: Accurate and effective? International Journal of Speech-Language Pathology, 16(1), 1-10. doi:10.3109/17549507.2013.858773.

Caroline B. (2015). Exercise as an intervention for children with Autism Spectrum Disorder: Perspectives of education professionals. United Kingdom: Birmingham City University. Retrieved from https://espace.mmu.ac.uk/583523/1/Caroline\%20Dissertation.pdf.

Dennison, P. E. (2003). What are Edu-K's three dimensions? Retrieved August 3, 2008, from http://www.braingym.org/faq.html.

Donnelly, J. E., Hillman, C. H., Castelli, D., Etnier, J. L., Lee, S., Tomporowski, P. SzaboReed, A. N. (2016). Physical activity, fitness, cognitive function, and academic achievement in children: A systematic review. Medicine and Science in Sports and Exercise, 48(6), 1197-1222. Retrieved from https://www.ncbi.nlm.nih.gov/pmc/articles/PMC4874515/

Fang, Q., Aiken, C. A., Fang, C., \& Pan, Z. (2019). Effects of exergaming on physical and cognitive functions in individuals with autism spectrum disorder: a systematic review. Games for Health Journal, 8(2), 74-84.

Frith, U., \& Happe, F. (1994). Language and Communication in Autistic Disorders. Philosophical Transaction of the Royal Society Biological Science, 346(1315): 97-104. Doi 10.1098/rstb.1994.0133.

Goldman, A. I. (1989). Interpretation psychologized. Mind and Language 4: 161-185.

Have, M., Nielsen, J. H., Ernst, M. T., Gejl, A. K., Fredens, K., Grøntved, A., \& Kristensen, P. L. (2018). Classroom-based physical activity improves children's math achievement-A randomized controlled trial. PloS One, 13(12), e0208787.

Hayes, J. A., Baylot Casey, L., Williamson, R., Black, T., \& Winsor, D. (2013). Educators' readiness to teach children with autism spectrum disorder in an inclusive classroom. The Researcher, 25(1), 67-78. Retrieved from http://www.nrmera.org/wpcontent/uploads/2016/02/Researcherv25n1Hayes_et-al.pdf https://www.ncbi.nlm.nih.gov/pmc/articles/PMC5357286/

Hays, J., \& Reinders, H. (2020) Sustainable Learning and Education: A Curriculum for the Future. International Review of Education, 66, 29-52.

Hughes, C., Soares-Boucaud, I., Hochmann, J. \& Frith, U. (1997). Social behaviour in pervasive developmental disorders: Effects of informant, group and 'theory-of mind. European Child \& Adolescent Psychiatry, 6, 191-198.

Horlin, C., Falkmer, M., Parsons, R., Albrecht, M. A., \& Falkmer, T. (2014). The cost of autism spectrum disorders. PloS one, 9(9). doi:10.1371/journal.pone.0106552 
Jiang, H., Cai, C., Ma, X., Yang, Y. \& Liu, J. (2018). Smart home based on WiFi sensing: A survey, IEEE Access, 6, 13317-13325.

Jones, C. (2014). To evaluate the effectiveness of participation in specific motor learning activities, on the academic learning areas of grade 2 learners. (Theses and dissertation, Degree Master of Arts, University of Pretoria, South Africa). Retrieved from https://repository.up.ac.za/bitstream/handle/2263/50631/Jones_Evaluate_2015.pdf?sequenc $\mathrm{e}=1$ \&isAllowed $=\mathrm{y}$

Kall, L. B., Nilsson, M., \& Linden, T. (2014). The impact of a physical activity program on academic achievement in a Swedish elementary school setting. Journal of School Health, 84(8), 473-480. doi: 10.1111/josh.12179.

Karen L. Bierman, C. E., Domitrovich, R. L., Nix, S. D., Gest, J. A., Welsh, M. T., Greenberg, C. Blair., Keith E. N., \& Sukhdeep, G. (2008). Promoting Academic and SocialEmotional School Readiness: The Head Start REDI Program. Child Development 79(6): 1802-1817. Retrieved from Doi: 10.1111/j.1467-8624.2008.01227.x https://www.ncbi.nlm.nih.gov/pmc/articles/PMC3549580/\#R5

Kjellmer L., Hedvall A., Fernell E., Gillberg C., \& Norrelgen F. (2011). Language and communication skills in preschool children with autism spectrum disorders: Contribution of cognition, severity of autism symptoms, and adaptive functioning to the variability. International Journal of Research in Developmental Disabilities, (33)1: 1-306. https://doi.org/10.1016/j.ridd.2011.09.003

Kosmas, P., Ioannou, A., \& Zaphiris, P. (2019). Implementing embodied learning in the classroom: effects on children's memory and language skills. Educational Media International, 56(1), 59-74.

Krog, S. (2010). Movement programmes as a means of learning readiness. University of South Africa, Pretoria. Retrieved from http://uir.unisa.ac.za/bitstream/handle/10500/3514/thesis_krog_s.pdf?sequence=1\&isAllow $\mathrm{ed}=\mathrm{y}$

Laurent, Amy \& Rubin, Emily. (2004). Challenges in Emotional Regulation in Asperger Syndrome and High-Functioning Autism. Topics in Language Disorders, 24, 286-297. http://doi.org/10.1097/00011363-200410000-00006

Lee, J. S. (2014). The relationship between student engagement and academic performance: Is it a myth or reality. The Journal of Education Research, 107(3), 177-185. doi: $10.1080 / 00220671.2013 .807491$

Lin, Y., \& He, Y. (2019). Does Bilingual Instruction impact students' Academic performance in Content-Based Learning? Does Bilingual Instruction Impact Students'

Lindsay, S., Proulx, M., Thomson, N., \& Scott, H. (2013). Educators' challenges of including children with autism spectrum disorder in mainstream classrooms. International Journal of Disability, Development and Education, 60(4), 347-362. doi :10.1080/1034912X.2013.846470 
Lisa A. R., \& Natacha A. (2013). Autism Spectrum Disorders: Identification and Diagnosis. National Association of School Psychologists Communiqué Handout 38(8). Retrieved from http://www.squareonemd.com/wp-content/uploads/2013/07/Autism-Spectrum-DisordersDr.-Ruble.pdf

Low, H. M., \& Lee, L. W. (2011). Teaching of Speech, Language and Communication Skills for Young Children with Severe Autism Spectrum Disorders: What Do Educators Need to Know? New Horizons in Education, 59 (3), 16-27.

Ma, X., Yao, T., Hu, M., Dong, Y., Liu, W., Wang, F. \& Liu, J. (2019). A survey on deep learning empowered IoT applications, IEEE Access, 7, 181721-181732.

Nagarkar, R., Rokade, p., \& Malwade, M. (2018). The effectiveness of cognitive acquisition activity on quality of life in autism spectrum disorder. International Journal of Healthcare and Biomedical Research, 6(2): 11-16

National Health and Morbidity Survey (2015). Non Communicable diseases, Risk-factors, and other Health problems, Volume 2. Retrieved from http://iku.moh.gov.my/images/IKU/Document/REPORT/nhmsreport2015vol2.pdf

Qi Meng (2017). Interventions promoting academic engagement for children with ASD in general education classroom. A systematic literature review. Retrieved from http://www.diva-portal.se/smash/get/diva2:1106562/FULLTEXT01.pdf

Razali, N. M,., Toran, H., Kamaralzaman, S., Salleh, N. M. \& Mohd. Yasin, M. H. (2013). Teachers' perceptions of including children with autism in a preschool. Asian Social Science, 9(12). Retrieved from http://www.ccsenet.org/journal/index.php/ass/article/view/30079.

Robin L. (2017) Educating Students with Autism Spectrum Disorders: Partnering with Families for Positive Outcomes. New York: SAGE Publications.

Renzo, M., Castelbianco, F. B., Racinaro, L., Vanadia, E., \& Rea, M. (2017). The Profile in Children with Autistic Spectrum Disorders: Clinical Assessments and Implications for Therapy. Autism Open Access, 7(3); 1-8. doi:10.4172/2165-7890.1000209.

Ribeiro de Oliveira, L., Brian, J., Kelly, E., Beal, D., Nicolson, R., Georgiades, S., Laboni, A., Fragiadakis, S. D., Ristic, L., Anagnostou, E., Sanjeevan, T. (2020). Exploring the use of the verbal intelligence quotient as a proxy for language ability in autism spectrum disorder. Research in Autism Spectrum Disorder, 73, 1-10.

Satu, E., \& Helvi, K. (2008). The qualitative content analysis process. Journal of Advanced Nursing 62(1), 107-115. Retrieved from Doi: 10.1111/j.1365-2648.2007.046569.x

Spain, D., Blainey, S. H., \& Vaillancourt, K. (2017). Group cognitive behaviour therapy (CBT) for social interaction anxiety in adults with autism spectrum disorders (ASD). Research in Autism Spectrum Disorders, 41, 20-30.

Sparapani, N., Morgan L., Reinhardt V. P., Schatschneider, C., Wetherby, A. M. (2016). 
Evaluation of Classroom Active Engagement in Elementary Students with Autism Spectrum Disorder. Journal of Autism Development Disorder, 46(3):782-96. Doi: 10.1007/s10803-015-2615-2. Retrieved from http://doi.org/10.1007/s10803-015-2615-2

Steiner, A. M., Goldsmith, T. R., Snow, A. V., \& Chawarska, K. (2012). Practitioner's guide to assessment of autism spectrum disorders in infants and toddlers. Journal of autism and developmental disorders, 42(6), 1183-1196. doi: 10.1007/s10803-011-1376-9

Sulistyoi, M., Choiri, A. S., \& Furqon H. (2017). Decreasing Tantrum of Child with Autism Using Cognitive acquisition. European Journal of Special Education Research, 2(2), Retrieved from https://zenodo.org/record/242907\#.Wzoul9IzZdh.

Vazou, S., Smiley-Oyen, A. (2014) Moving and academic learning are not antagonists: acute effects on executive function and enjoyment. J Sport Exerc Psychol. 36(5):474-85. doi: 10.1123/jsep.2014-0035.

Van Tongerloo, M. A., van Wijngaarden, P. J., van der Gaag, R. J., \& Lagro-Janssen, A. L. (2014). Raising a child with an Autism Spectrum Disorder:'If this was a partner relationship, I would have quit ages ago'. Family practice, 32(1), 88-93. Doi :10.1093/fampra/cmu076.

Zwaigenbaum, L., Bryson, S., \& Garon, N. (2013). Early identification of autism spectrum disorders. Behavioural Brain Research, 251, 133-146. doi:10.1016/j.bbr.2013.04.004. 